\title{
Home Deliveries in Rural Assiut Governorate: The Role of The Trained Nurse Midwife
}

\author{
Omaima El-Gibaly ${ }^{1}$, Eman M. M. Monazea ${ }^{1}$, Ghada S.T. Al-Attar ${ }^{1}$ \\ ${ }^{1}$ Public Health \& Community Medicine Department, Faculty of Medicine, Assiut \\ University, Assiut, Egypt
}

Received: March $2017 \quad$ Accepted : May 2017

\begin{abstract}
Background: Skilled attendance at delivery is a key intervention to reduce maternal and neonatal deaths. Rural women may be less likely to be attended by skilled providers. In Egypt, Ministry of health and Population (MOHP) had undertaken tremendous efforts in training nurses on midwifery skills. Objective: The study aimed to estimate proportion of home deliveries attended by the trained nurse midwives, to identify factors associated with choosing home birth attendants and to describe midwifery practice and satisfaction of the midwives. Methods: A cross sectional survey was conducted in 30 randomly selected villages of Assiut Governorate. Mothers who gave birth at home in year 2012 and all midwives who work in the selected villages were interviewed. Results A total of 319 women and 33 midwives were included in the study. Daya was the birth attendant in $40.4 \%$ of deliveries while midwives attended $14.4 \%$. The percentage of using skilled birth attendants was significantly higher in women who were aware about midwives and who were previously delivered by skilled persons $(\mathrm{p}<0.001)$. About $21 \%$ of midwives reported they have fear to deliver a woman, 54.5\% prefer doctor presence with them. Conclusion Less than one fifth of women were attended by the midwives. Information about midwives and not having a previous delivery by a daya were the factors that determine choosing of the nurse midwife as a birth attendant. Developing an awareness campaign to increase women knowledge about the availability and competence of midwives might encourage using them as birth attendants.
\end{abstract}

Key words: Home delivery, Rural, Trained nurse midwife, Assiut, Egypt.

Corresponding author: Omaima El-Gibaly Mohamed Helmy Email: oelgibaly@yahoo.com

\section{Introduction}

Egypt made a remarkable progress in educing maternal mortality rate (MMR) to achieve the 5th Millennium Development goal (which is a reduction of MMR to 43.2 maternal death/100,000 live births by 2015). Between 1992 and 2015, Maternal Mortality Rate (MMR) has declined from 174 maternal death $/ 100,000$ live births to 43.5 maternal death /100,000 live births. ${ }^{1,2}$ However, Assiut Governorate in Upper Egypt was among the highest governorates in maternal deaths; 60 - 65 maternal death /100,000 live births in 2013. ${ }^{3}$

Previous studies reported that about half of maternal deaths occurred at home $e^{4,5}$ due to delivery complications. ${ }^{6}$ According to Egyptian Ministry of Health and population (MOHP), it was reported that maternal deaths at home accounted for $22 \%$ in 2012. ${ }^{1}$ Home deliveries are still high and are more frequent in rural Upper Egypt compared to the rest of the country, reaching a level of $50 \% .^{7}$ In home deliveries the daya 
'traditional birth attendant' (TBA) is still a major service provider ${ }^{8}$ attending $38 \%$ of deliveries in rural Upper Egypt. ${ }^{7}$ Home deliveries carried out by TBAs are more likely to predispose to neonatal and maternal infections ${ }^{9}$ and uterine or vaginal prolapse. ${ }^{10}$ Also, in a secondary analysis study using Egypt Demographic Health Survey (EDHS 2000); it was found that $27 \%$ and $30 \%$ of still births and early neonatal deaths respectively occur in home deliveries. ${ }^{11}$

Skilled health attendance at delivery is essential for eliminating every preventable maternal and neonatal death. ${ }^{12,13}$ In Egypt, access to this service has improved with $92 \%$ of women delivering with the support of a skilled birth attendant in 2014, compared to 35 $\%$ in $1988 .^{14}$ In developing countries, urban- rural difference was identified in another study using maternal health care, with rural women less likely to be attended by skilled health provider and more likely to give birth in a non-medical setting. ${ }^{15}$

Determinants of skilled attendance at birth or facility delivery in low and middle income countries have been studied. It was found that factors most consistently associated with receiving skilled care were higher maternal age, low parity, higher maternal education and higher household economic resources. ${ }^{16}$ However, this former study combines the skilled birth attendant and facility delivery, while we need to understand more what determines the women's choice of asking a daya instead of the licensed trained nurse midwife to provide her with care at birth at home. On the other hand, as nurses and midwives are the front-line service providers in rural areas, however, they face many challenges including educational and financial availability of resources for training, insufficient work force, leadership issues and service delivery constraints. ${ }^{17}$ In Egypt, the Ministry of Health and Population
(MOHP) took many efforts in training nurses on midwifery skills. However, since the start of that training program at year 2000, up to the authors' knowledge, no study was conducted to estimate the training impact on home deliveries and whether it needs to be upgraded to meet women's need. This survey could provide decision makers with evidence-based knowledge on ways to improve skills of midwives and hence increase their using as birth attendants which will be reflected on improving women's health eventually.

The objectives of this study are: (1)

To estimate the proportion of the home deliveries attended by the trained nurse midwives in rural Assiut. (2) To identify the factors associated with the choice of birth attendants in home delivery. (3) To describe midwifery practice and satisfaction of the trained midwives on home deliveries.

\section{Method}

Study design \& site: A cross sectional household survey was conducted in rural areas of Assiut Governorate which is one of Upper Egypt Governorates; it has a population of 4,621,135 million (72.8\% rural versus $27.2 \%$ urban). Rural areas include 235 villages distributed within 11 districts (18). Thirty villages were randomly selected based on the availability of at least one trained nurse mid-wife in the rural health unit of each village.

Study Population: The target population was mothers who gave birth at home in year 2012 or had a complicated home delivery and were transferred to a health facility. In addition to all trained nurse midwives work in the selected villages.

\section{Sample size and sampling strategy}

Sample size was calculated using Epi Info 2000, version 1.1.2 (Center for Disease Control and Prevention, Atlanta, Georgia, USA), based on Egyptian DHS, 2008 , which stated that the percentage of unskilled birth attendants was $21 \%$ and 
using $95 \%$ confidence interval, the calculated sample size was 708 mothers which was increased to 750 to safeguard against drop out. According to EDHS 2008, home deliveries were $50 \%$ in rural Upper Egypt ${ }^{(7)}$, so, to reach our target women (who delivered at home), the households of 1,500 live births (double of the sample size) were selected. From birth register of each selected village in 2012, a simple random sample of 50 births was identified. The households of 1,500 live births (50 births / village) were visited, at first the mother was asked about the place of her child delivery and if it was at home she was invited to participate in the study. However, out of these visited households, only 319 $(21.3 \%)$ were home deliveries, 905 $(60.3 \%)$ were institutional deliveries (hospital or private clinic) and 276 households (18.4\%) were dropouts for traveling, refusal, changed residence or inability to find addresses.

\section{Study instrument}

A semi-structured questionnaire was designed and pretested in 20 mothers in Awlad Ibrahim village and were not involved in the survey. It included questions about demographic, reproductive and service variables such as: respondent age, education, work status, parity, place and birth attendant of previous delivery, any complications in the previous delivery, received antenatal care, planned home delivery and knowledge about the presence of trained midwives in the village. Also, a semistructured questionnaire was developed for interviewing the nurses which included data about age, parity, residence, duration of midwifery license, number of attended home deliveries in the last month and if the nurse referred a complicated case. In addition, 6 statements about self-view and perceived satisfaction were asked to the nurse and she replied by agree, not agree or neither agree or not agree. Data collection was carried out by 6 trained interviewers in June, 2013.

The study was approved by the ethics committee in the Faculty of Medicine, Assiut University. Verbal informed consent was obtained from all participants to perform the interviews. The participation in the study was voluntary and confidentiality was warranted.

\section{Statistical analysis}

Data analysis was conducted using SPSS for Windows version 16 (SPSS Inc., Chicago, Illinois, USA). Three constructed variables were assumed: the first one was delivery by skilled birth attendants (physicians, nurses and midwives) versus non skilled birth attendants (dayas, family relatives), the second one was delivery by a trained nurse midwife versus the other birth attendants and the third variable was births by dayas versus the other birth attendants. Factors associated with using either skilled birth attendants or trained nurse midwife or dayas were explored by Chi square test. Logistic regression model was done to predict correlates of skilled birth attendance only. Significant variables in bivariate analysis in addition to other non-significant independent variables were added to the model based on conceptual framework. The level of statistical significance was set at $\mathrm{p}$-value less than 0.05 .

\section{Results}

As for women side of the story: Out of 1500 live births, only 319 (21.3\%) were home deliveries. So, a total of 319 married women were included in the study. Their ages range from 17- 43 with a mean age of $27.82 \pm 5.62$ years. About half of them were illiterate (52\%), almost all were housewives (97.0\%); the majority were Muslims (93\%). For $13.8 \%$ of women, the child born was their first birth (Primipara).

Based on the fact that all our study participants of mothers (319) had their 
Table (1): Current home birth attendants and attitude of the women towards them, Assiut, 2013.

\begin{tabular}{|l|r|r|}
\hline \multicolumn{1}{|c|}{ Variable } & $\begin{array}{c}\text { Frequency } \\
\text { No.=319 }\end{array}$ & $\begin{array}{c}\text { Percentage } \\
\text { \% }\end{array}$ \\
\hline Birth attendant & 129 & 40.4 \\
\hline Daya & 39 & 12.2 \\
\hline RHU Nurse [not trained] & 46 & 14.4 \\
\hline Trained Nurse Midwife & 41 & 12.9 \\
\hline Other nurse elsewhere & 36 & 11.3 \\
\hline Mother in-law & 11 & 3.4 \\
\hline Ob. \& Gyn. Doctor & 8 & 2.5 \\
\hline General practitioner & 2 & 0.6 \\
\hline Alone & 7 & 2.2 \\
\hline Other & 308 & 96.6 \\
\hline Satisfied with birth attendant & 257 & 80.6 \\
\hline $\begin{array}{l}\text { Call upon same birth attendant in the next } \\
\text { delivery }\end{array}$ & & 32.6 \\
\hline Call upon midwives for the next delivery & 104 & \\
\hline
\end{tabular}


Table (2) Factors associated with the choice of various types of birth attendants at home delivery, Assiut, 2013.

\begin{tabular}{|c|c|c|c|c|c|c|c|}
\hline \multirow[t]{2}{*}{ Variable } & \multirow[t]{2}{*}{$\begin{array}{c}\text { Total } \\
\text { number } \\
(319)\end{array}$} & \multicolumn{2}{|c|}{$\begin{array}{c}\text { Skilled provider } \\
\text { vs. others } \\
\text { No. }(\%)\end{array}$} & \multicolumn{2}{|c|}{$\begin{array}{c}\text { Trained midwives } \\
\text { vs. others } \\
\text { No. }(\%)\end{array}$} & \multicolumn{2}{|c|}{$\begin{array}{c}\text { Daya vs. others } \\
\text { No. }(\%)\end{array}$} \\
\hline & & \begin{tabular}{|l|l} 
Skilled & \\
\end{tabular} & Others & Midwife & Others & Daya & Others \\
\hline \multicolumn{8}{|c|}{ Age of woman in years } \\
\hline Less than 20 & 12 & $3 \quad(25.0)$ & $9(75.0)$ & $1(8.3)$ & 11(91.7) & $8(66.7)$ & $4(33.3)$ \\
\hline $20-$ & 193 & $90(46.6)$ & $103(53.4)$ & $25(13.0)$ & $168(87.0)$ & $74(38.3)$ & $119(61.7)$ \\
\hline $30-$ & 98 & $45(45.9)$ & $53(54.1)$ & $16(16.3)$ & $82(83.7)$ & $40(40.8)$ & $58(59.2)$ \\
\hline $40+$ & 16 & $7 \quad(43.8)$ & $9(56.2)$ & $4(25)$ & $12(75.0)$ & $7(43.8)$ & $9(56.2)$ \\
\hline \multicolumn{8}{|l|}{ Education } \\
\hline Illiterate & 167 & $67(40.1)$ & $100(59.9)$ & $20(12.0)$ & $147(88.0)$ & $74(44.3)$ & $93(55.7)$ \\
\hline Below secondary & 48 & $23(47.9)$ & $25(52.1)$ & $4(8.3)$ & $44(91.7)$ & $18(37.5)$ & $30(62.5)$ \\
\hline Secondary \& above & 104 & $55(52.9)$ & $49(47.1)$ & $22(21.2)^{*}$ & $82(78.8)$ & $37(35.6)$ & $67(64.4)$ \\
\hline \multicolumn{8}{|l|}{ Work Status } \\
\hline Housewife & 310 & $141(45.5)$ & $169(54.5)$ & $44(14.2)$ & $266(85.8)$ & $125(40.3)$ & $185(59.7)$ \\
\hline Work for pay & 9 & $4(44.4)$ & $5(55.6)$ & $2(22.2)$ & $7(77.8)$ & $4 \quad(44.4)$ & $5(55.6)$ \\
\hline \multicolumn{8}{|l|}{ Religion } \\
\hline Muslim & 296 & 138 (46.6) & $158(53.4)$ & $44(14.9)$ & $252(85.1)$ & $115(38.9)$ & $181(61.1)$ \\
\hline Christian & 23 & $7(30.4)$ & $16(69.6)$ & $2(8.7)$ & $21(91.3)$ & $14(60.9)^{*}$ & $9(39.1)$ \\
\hline \multicolumn{8}{|c|}{ Education of husband } \\
\hline Illiterate & 116 & $44(37.9)$ & $72(62.1)$ & $14(12.1)$ & 102( & $57(49.1)$ & $59(50.9)$ \\
\hline Below & 32 & $12(37.5)$ & $20(62.5)$ & $6 \quad(18.8)$ & $26(81.2)$ & $13(40.6)$ & $19(59.4)$ \\
\hline Secondary \& above & 171 & $89(52.0) *$ & $82(48.0)$ & $26(15.2)$ & $145(84.8)$ & $59(34.5)^{*}$ & $112(65.5)$ \\
\hline \multicolumn{8}{|c|}{ Family composition } \\
\hline Extended family & 218 & $98(45.0)$ & $120(55.0)$ & $30(13.8)$ & $188(86.2)$ & $92(42.2)$ & $126(57.8)$ \\
\hline Nuclear family & 101 & $47(46.5)$ & $54(53.5)$ & $16(15.8)$ & $85(84.2)$ & $37(36.6)$ & $64(63.4)$ \\
\hline \multicolumn{8}{|l|}{ Parity } \\
\hline First baby & 44 & $25(56.8)$ & $19(43.2)$ & $9 \quad(20.5)$ & $35(79.5)$ & $17(38.6)$ & $27(61.4)$ \\
\hline Multiparous & 275 & $120(43.6)$ & $155(56.4)$ & $37(13.5)$ & $238(86.5)$ & $112(40.7)$ & $163(59.3)$ \\
\hline \multicolumn{8}{|c|}{ Place of last delivery $($ No. $=275)$} \\
\hline At home & 215 & $90(41.9)$ & $125(58.1)$ & $31(14.4)$ & $184(85.6)$ & $88(40.9)$ & $127(59.0)$ \\
\hline Hospital/clinic & 60 & $30(50.0)$ & $30(50.0)$ & $6(10.0)$ & $54(90.0)$ & $24(40.0)$ & $36(60.0)$ \\
\hline \multicolumn{8}{|c|}{ Birth attendant in last delivery $($ No. $=275)$} \\
\hline Skilled & 133 & $93(69.9)^{* *}$ & $40(30.1$ & $29(21.8)^{* * *}$ & $104(78.2)$ & $29(21.8)$ & $104(78.2)$ \\
\hline Non skilled & 142 & $27(19.0)$ & $115(81.0)$ & $8(5.6)$ & $134(94.4)$ & $83(58.5)^{* *}$ & $59(41.5)$ \\
\hline \multicolumn{8}{|c|}{ Complication in last delivery $($ No. $=275)$} \\
\hline Yes & 18 & $11(61.1)$ & $7(38.9)$ & $3(16.7)$ & $15(83.3)$ & $6(33.3)$ & $12(66.7)$ \\
\hline No & 257 & $109(42.4)$ & $148(57.6)$ & $34(13.2)$ & $223(86.8)$ & $106(41.2)$ & $151(58.8)$ \\
\hline \multicolumn{8}{|c|}{ If pregnancy wanted } \\
\hline Yes & 276 & $127(46.0)$ & $149(54.0)$ & $39(14.1)$ & $237(85.9)$ & $112(46.6)$ & $164(59.4)$ \\
\hline No & 43 & $18(41.9)$ & $25(58.1)$ & $7 \quad(16.3)$ & $36(83.7)$ & $17(39.5)$ & $26(60.5)$ \\
\hline \multicolumn{8}{|l|}{ Get antenatal care } \\
\hline Yes & 264 & $124(47.0)$ & $140(53.0)$ & $41(15.5)$ & $223(84.5)$ & $105(39.8)$ & $159(60.2)$ \\
\hline No & 55 & $21(38.2)$ & $34(61.8)$ & $5(9.1)$ & $50(90.9)$ & $24(43.6)$ & $31(56.4)$ \\
\hline \multicolumn{8}{|c|}{ Planned home delivery } \\
\hline Yes & 217 & $96(44.2)$ & $121(55.8)$ & $38(17.5)^{*}$ & $179(82.5)$ & $89(41.0)$ & $128(59.0)$ \\
\hline No & 102 & $49(48.0)$ & $53(52.0)$ & $8(7.8)$ & $94(92.2)$ & $40(39.2)$ & $62(60.8)$ \\
\hline \multicolumn{8}{|c|}{ Know about midwives } \\
\hline Yes & 103 & $57(55.3)^{*}$ & $46(44.7)$ & $43(41.7)^{* * *}$ & $60(58.3)$ & $35(34.0)$ & $68(66.0)$ \\
\hline No & 216 & 88 (40.7) & $128(59.3)$ & $3(1.4)$ & $213(98.6)$ & $94(43.5)$ & $122(56.5)$ \\
\hline
\end{tabular}

Chi square test: $* \mathrm{P}<0.05, * * \mathrm{P}<0.01, * * * \mathrm{P}<0.001$ 
Table (3): Logistic regression analysis of factors associated with skilled birth attendants, Assiut, 2013.

\begin{tabular}{|l|l|l|}
\hline \multicolumn{1}{|c|}{ Variables } & P-value & \multicolumn{1}{|c|}{$\begin{array}{c}\text { Adjusted OR } \\
(\mathbf{9 5 \%} \text { C.I. })\end{array}$} \\
\hline Age of woman $(\geq$ 30 years) & .238 & $0.67(0.35-1.30)$ \\
\hline Woman education (secondary / above secondary) & .835 & $1.09(0.47-2.54)$ \\
\hline Husband education (secondary / above secondary) & .039 & $3.24(1.06-9.90)$ \\
\hline Live in extended family & .576 & $.84(0.46-1.54)$ \\
\hline Muslim women & .164 & $2.15(0.73-6.33)$ \\
\hline Number of children $(\geq 3)$ & .448 & $0.75(0.35-1.59)$ \\
\hline Previous delivery complication & .667 & $1.287(0.41-4.05)$ \\
\hline Previous skilled birth attendance & .000 & $11.8(6.28-22.22)$ \\
\hline Wanted pregnancy & .891 & $0.94(0.41-2.19)$ \\
\hline Received antenatal care & .438 & $0.74(0.35-1.58)$ \\
\hline Planned home delivery & .139 & $1.56(0.87-2.81)$ \\
\hline Awareness about midwives & .083 & $1.66(0.94-2.93)$ \\
\hline
\end{tabular}

OR: odds ratio, CI: Confidence interval

Table (4): Midwifery practice and satisfaction of the trained nurse midwives, Assiut, 2013.

\begin{tabular}{|l|r|r|}
\hline \multicolumn{1}{|c|}{ Variables } & $\begin{array}{c}\text { Frequency } \\
\text { No.=33 }\end{array}$ & $\begin{array}{c}\text { Percentage } \\
\%\end{array}$ \\
\hline No. of home births attended in the last month & 11 & 33.3 \\
\hline 0 & 16 & 48.5 \\
\hline $1-4$ & 6 & 18.2 \\
\hline$\geq 5$ & $3(0-25)$ \\
\hline Median (range) & \multicolumn{3}{|c|}{} \\
\hline No. of referrals in the last month & 22 & 66.7 \\
\hline 0 & 3 & 9.1 \\
\hline 1 & 8 & 24.2 \\
\hline$\geq 2$ & $0(0-8)$ \\
\hline Median (range) & 24 & 72.7 \\
\hline can deliver a woman efficiently alone & 31 & 93.9 \\
\hline perceived self efficacy to refer a woman timely & 7 & 21.1 \\
\hline have fear to deliver a woman & 18 & 54.5 \\
\hline prefer the presence of doctor with them & 33 & 100.0 \\
\hline satisfied with the midwifery training & 31 & 93.9 \\
\hline need more support & \multicolumn{2}{|c|}{} \\
\hline
\end{tabular}




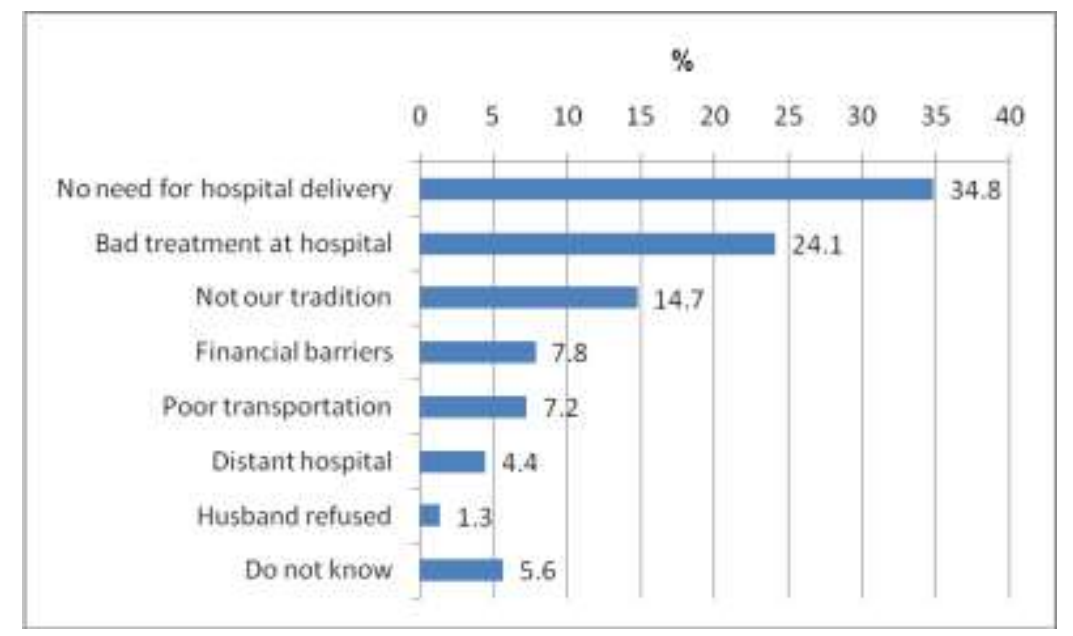

Fig (1) Reasons given by the studied women for preferring home versus hospital delivery, Assiut, 2013

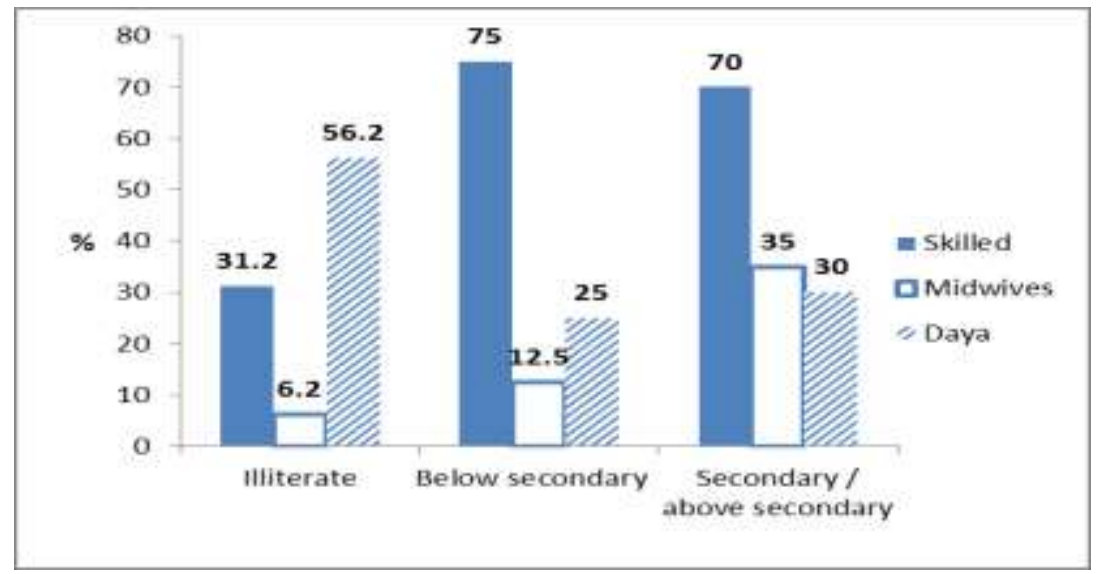

Fig (2): The percent of using birth attendants by the education level of first time mothers

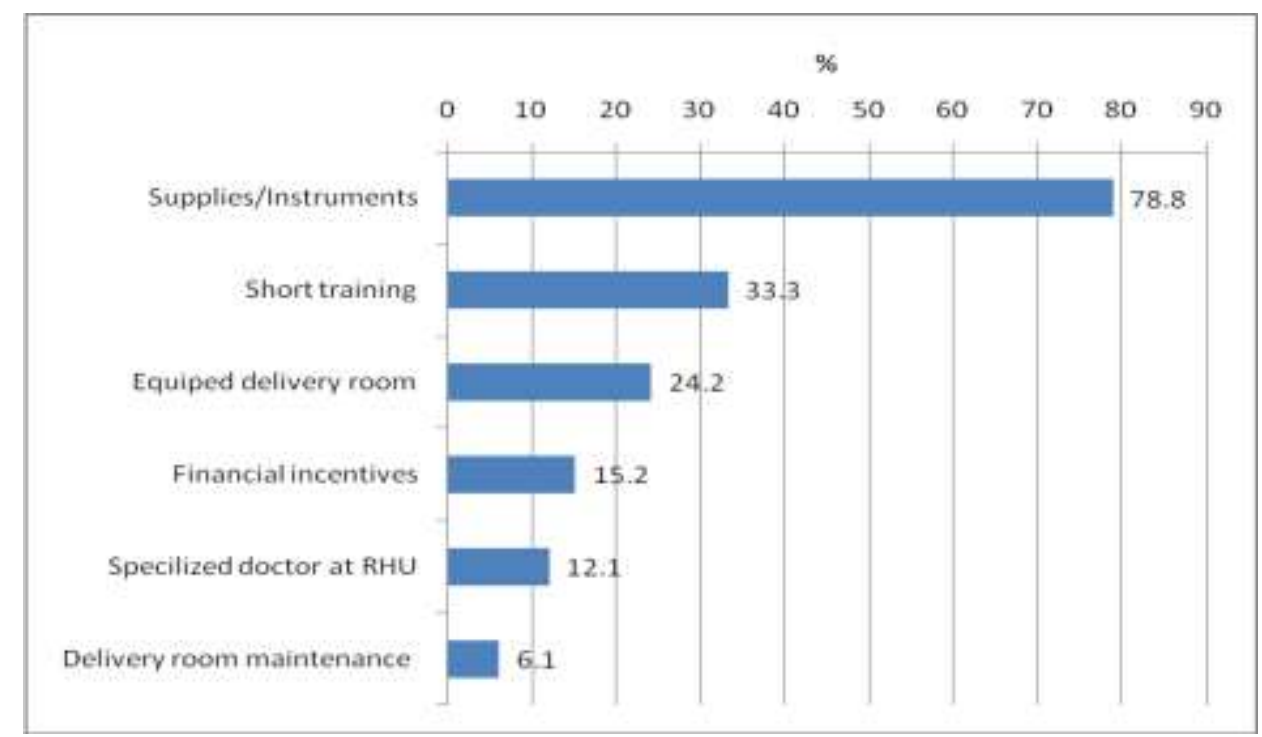

Fig (3): Type of support requested by the trained nurse midwives, Assiut, 2013. 
last delivery (prior to the survey) at home, the daya was the birth attendant in $40.4 \%$ of cases, nurses attended $39.5 \%$ (14.4\% of them were midwives, other RHU nurses represented $12.2 \%$, other nurses elsewhere $12.9 \%$ ), the mother-inlaw attended $11.3 \%$, and doctors $6 \%$. Almost all the participants were satisfied with the service they received from their birth attendants. The decision of 'who' to call upon in the next delivery is very much determined by woman's previous birth experience, as $80.6 \%$ of women would call upon the same person who attended their last delivery. When women were asked whether they would call upon the midwives to be their birth attendants next time, $104 \quad(32.6 \%)$ responded yes (Table 1).

Women would prefer a home delivery instead of hospital delivery mainly because they perceived a hospital delivery as 'unnecessary' (34.8\%), not their tradition $(14.7 \%)$, bad experience with hospital delivery (24.1\%), financially expensive $(7.8 \%)$ and $7.2 \%$ reported difficult transportation (Fig. 1). Table (2) presents the factors that were associated with the choice of birth attendants. Women under age 20 years were mostly using the daya as a birth attendant $(66.7 \%)$. However, age of woman was not a significant factor. The percentage of using skilled birth attendants increased with increasing education level of the women. High education was significantly associated with using midwives $(p=0.048)$. High education of the husband was significantly associated with using skilled birth attendants $(\mathrm{p}=0.04)$ and low educational level was associated with using of daya $(p=0.046)$. Daya was more called upon by Christian women than Moslems $\quad(60.9 \%$ vs. $38.9 \%$, p $=0.038)$. Type of birth attendants was not affected by the parity, received antenatal care or whether the pregnancy wanted by the woman or not. Type of birth attendants in previous delivery was significantly associated with choosing of currently birth attendants, as the percentage of using skilled/midwives was significantly higher in women previously delivered by skilled persons $(p<0.001)$. Awareness of the presence of midwives at the same village was significantly related with choice of them as birth attendants $(\mathrm{p}<0.001)$. However, only $32.3 \%$ of women were aware about midwives. Also, the percentage of using midwives as birth attendants was significantly high in women who planned for home delivery $(\mathrm{p}=0.022)$. Only 18 out of 275 women have experienced complications in their previous births, 11 of them $(61.1 \%)$ used skilled birth attendants compared to $42.4 \%$ of women who reported no complications but the difference was not significant. For first time mothers, the only factor that significantly associated with using skilled birth attendants was their education level, $\mathrm{p}=0.034$ (Fig. 2) and using midwives was significantly related to their awareness about them ( $p$ < 0.001). In multivariate logistic regression analysis, being delivered by skilled birth attendant in previous birth and high level of husband education were the only significant predictors for being currently delivered by a skilled birth attendant; $\mathrm{OR}=11.8,95 \%$ confidence interval $(\mathrm{CI})$ : $6.28-22.22$ and 3.24, 95\% CI: $1.06-$ 9.90, respectively (Table 3 ).

The Nurse Midwife side of the story

A total of 33 nurses were successfully interviewed. Their mean age in years was $31.27 \pm 6.84$. Twenty seven nurses $(81.8 \%)$ were married and had a mean number $2.27(\mathrm{SD}=1.84)$ children. Only 13 nurses (39.4\%) were residing in the same village where they work. The duration of getting their license ranged from 11- 91 months (median 42). Regarding the practice of midwives in the last month (prior to the survey), the median number of deliveries attended was 3 with a range from 0 to 25 
deliveries and the average number of referrals to hospitals or a doctor was less than one with a range from 0 to 8 (Table 4). About $73 \%$ of the nurses perceived confidence in delivering a woman efficiently alone and most of them (93.9\%) perceived self-ability to refer any complicated case to a hospital timely. However, $21.1 \%$ of nurses reported they fear to deliver a woman and $54.5 \%$ prefer the presence of doctor with them. Although, all nurses were satisfied with the midwifery training of MOHP, 93.9\% reported they need more support from MOHP (such as supplies/instruments, short training and financial incentives, Fig. 3) to be more efficient in practicing midwifery.

\section{Discussion}

The present study highlights that home delivery in rural areas is receding, and institutional delivery is on the rise. However, there is a considerable sector (20\%) of the rural population who may continue to have a home delivery. This is in consistent with the finding of EDHS 2014, as the percent of births in health facilities was $76 \%$ in rural Upper Egypt. ${ }^{8}$ In agreement with another study ${ }^{19}$, this study found that daya is one of the preferred birth attendants by rural women in home deliveries. Less than one fifth of women (14.4\%) were delivered by a midwife compared to $40 \%$ who were attended by dayas. This could be, in part, explained by the low percentage of women who knew about the existence of midwives; only one third of our study sample knew about the midwives. More awareness lead to more using of midwives and higher rates of skilled attendance utilization especially among women who planned for home delivery $(\mathrm{p}=0.022)$. Only $6 \%$ of the home deliveries were attended by doctors, this indicates that most doctors attend deliveries either at private clinics or at hospitals but rarely at home. Women tend to deliver with the same birth attendant if a previous delivery went well and tend to change when they are dissatisfied. ${ }^{20,21,22}$ Having a contact with a skilled birth attendant was found to be one of the determinants of facility delivery. On the other hand, having a history of unskilled birth attendant would encourage further unskilled delivery. ${ }^{23}$ This was consistent with our findings as being delivered by daya in the previous delivery was in favour of being delivered by a daya in the following delivery and the percentage of using skilled attendants /midwives was significantly higher in women previously delivered by skilled provider $(\mathrm{p}<0.001)$. Moreover, $80.6 \%$ of women reported that they would call upon the same birth attended in the next delivery.

Consistent with other studies ${ }^{24,23}$, women education always plays a role in promoting better women health, those who completed their secondary education were more likely to deliver by a skilled attendant /midwives while illiterate women were more likely to choose dayas and this was more noticed in primiparous women. Also, higher husbands' education level was found to be a significant factor for skilled attendance at home delivery. Another study reported a similar finding. Education could increase the knowledge and awareness of the couple about health services and benefits of skilled birth attendance. $^{16}$

Women who use antenatal care are much likely to receive skilled attendance at delivery $^{25}$, which infers institutional delivery in most of studies. ${ }^{11}$ In this study, a great percentage of women received antenatal care $(82.8 \%)$, though this was an insignificant factor for choosing birth attendants. During antenatal care women who know that their pregnancy is going well may be encouraged to deliver at home without determining the birth attendant.

Multiparous women deliver at home more frequently than primiparous women $^{26}$ and also may not feel the need 
to receive skilled attendance if previous deliveries were uncomplicated. ${ }^{27}$ By contrast the first birth is considered to be more difficult and a facility delivery is recommended for primipara. ${ }^{28}$ Our study revealed that type of home birth attendants was not affected by the parity. It is noteworthy to mention that most of our studied women were multiparous $(86.2 \%)$ and parity may be associated with age of women and wantedness of pregnancy which found to be insignificant factors.

Unlike Yanagisawa et al., who found that history of delivery complications in the previous delivery was one of the determinants of skilled birth attendants. ${ }^{23}$ In our study, this variable was not significant which draw the attention to the non health factors that may influence the choice of the woman. However, it is noteworthy to mention that the percentage of women who had a history of complications was so small $(\mathrm{n}=18$, $6.6 \%)$.

Beliefs, norms and values related to women and child birth are closely linked to religion. ${ }^{16}$ Christian mothers in our study sought daya more than Muslims (60.9\% vs.38.9\%, p 0.038). This may be related to their socioeconomic status or that being a minority group, (23 mothers) may lead to their fear of discrimination which make them less likely to use health providers. ${ }^{29}$ Also, the study reveals that mothers live in extended families were less likely to use a skilled birth attendant than whom live in nuclear families $(42.2 \%$ vs. $36.6 \%)$ but the difference was not significant. Decision- making power of women may be affected by living in extended families and role of mother inlaw was evident in this study as they attended $11.3 \%$ of births.

Regarding reasons for home delivery, about $24 \%$ of women reported bad experience with hospital delivery. This finding is in line with other studies which suggest that poor quality of care and staff behaviour at institutions were disincentives to delivery at a health facility. ${ }^{30,31,32}$ Consistent with another study, we found that financial constraint did not seem to be a major reason for not seeking institutional delivery as it was reported by minority of women. ${ }^{8}$

Despite the small sample group of trained midwives in this study, the study has obtained important information about their midwifery practice. There is a high variability in the success of the midwives in getting a market niche, there are extremes either fully active or not at all as the number of home deliveries range from 0 to 25 per month. Although, all nurses were satisfied with the midwifery training of MOHP, most of them (93.9\%) reported they need more support to be more efficient in practicing midwifery and about half of them prefer presence of doctor with them which indicate low self-efficacy. Moreover, the trained nurse midwives face competition from others who provide delivery services at home; mainly the dayas and there was lack of marketing the services of the midwives in rural communities as well. These challenges are in agreement with the Nursing and Midwifery report of the WHO which emphasizes the educational, work place, financial and organizational obstacles midwives face in service delivery. ${ }^{17}$ In addition, nearly $60 \%$ of the trained NMW live in places other than the villages that they work at, which makes it difficult to build human relations \& trust between them and the residents of these villages.

\section{Conclusions}

and

\section{Recommendations}

Less than one fifth of women were delivered by the trained nurse midwives. Awareness of the presence of midwives at the same village, having a planned home delivery and not having a previous delivery by a daya were the factors that determine choosing of midwives. To encourage home delivery by the trained midwives, it might be effective to focus 
on intensive outreach in rural area by community based health workers, who could play a greater part in informing women about midwives and develop an awareness campaign to increase women knowledge about the availability of midwives and the difference between them and other non-trained nurses. Further research about midwifery practice is needed.

\section{Acknowledgements}

The authors would like to acknowledge UNFPA for funding data collection phase of this study.

\section{Conflicts of interest}

There are no conflicts of interest.

\section{References}

1. Maternal Mortality Bulletin (MMB). The second issue. Maternal and Child Health Directorate Cairo; 2013.

2. WHO. Trends in maternal mortality: 1990 to 2015: estimates by WHO, UNICEF, UNFPA, World Bank Group and the United Nations Population Division, 2015.

3. United Nations Development Program (UNDP) and the Ministry of Planning, Monitoring and Administrative Reform report. Egypt's progress toward Millennium Development Goals, 2015.

4. El Kady A, Saleh S, Gadalla S, Fortney $\mathbf{J}$ and Bayoumi H: Obstetric deaths in Menoufia Governorate, Egypt. British Journal of Obstetrics \& Gynecology 1989; 96: 9-14.

5. Kane Th, El-Kady A, Saleh S, Hage M, Stanback J and Potter L: Maternal mortality in Giza, Egypt: magnitude, causes and prevention. Studies in Family Planning 1992; 23 (1): 45-57.

6. killewo J., Anwar I., Bashir I., Yunus M. and Chakraborty J. . Perceived delay in healthcare-seeking for episodes of serious illness and its implications for safe motherhood interventions in rural Bangladesh, Journal of Health, Population, Nutrition 2006; 24(4): 403412.
7. El-Zanaty F, Way A. Egypt Demographic and Health Survey 2008. Cairo, Egypt: Ministry of Health and Population, National Population Council, El-Zanaty and Associates, and ORC Macro; 2009.

8. Das S., Bapat U., Shah More N., Chordhekar L., Joshi W., Osrin D. Prospective study of determinants and costs of home births in Mumbai slums. BMC Pregnancy and Childbirth 2010; 10: 38 .

9. Darmstadt G, Hassan M, Balsara Z, Winch P, Gipson R and Santosham M: Impact of clean delivery-kit use on newborn umbilical cord and maternal puerperal infections in Egypt. J. Health Popul. Nutr. 2009; 27 (6): 746-754.

10. Younis N, Khattab H, Zurayk H, ElMouelhy M, Amin M and Farag A: A community study of gynecological and related morbidities in rural Egypt. Studies in Family Planning 1993; 24(3): 175-186

11. Campbell O, Gipson R, El Mohandes A, Issa A, Matta N, Mansour $\mathrm{E}$ and Mohsen L.: The Egypt national perinatal/neonatal mortality study 2000 . Journal of Perinatoloty 2004; 24: 284289.

12. WHO. Reduction of maternal mortality: a joint WHO/UNFPA/UNICEF/Wmorld Bank statement. 1999, Geneva.

13. Lawn JE., Cousens S. and Zupan J. 4 million neonatal deaths: when? Where? Why?. Lancet 2005; 365 (9462): 891 900.

14. Ministry of Health and Population [Egypt], El-Zanaty and Associates [Egypt], and ICF International. Egypt Demographic and Health Survey 2014. Cairo, Egypt and Rockville, Maryland, USA: Ministry of Health and Population and ICF International 2015.

15. Say L, Raine R: A systematic review of inequalities in the use of maternal health care in developing countries: examining the scale of the problem and 
the importance of context. Bull WHO 2007; 85:812-819.

16. Gabrysch S. and Campbell OM. . Still too far to walk: literature review of the determinants of delivery service use. BMC Pregnancy and Childbirth 2009; 9:34. DOI: 10.1186/1471-2393-9-34.

17. WHO. WHO nursing and midwifery progress report (2008 - 2012). Geneva, Switzerland 2013.

18. Assiut Governorate website: Geographical features of Assiut. 2013. www.assiut.gov.eg.

19. Darmstadt GL, Hussein MH, Winch PJ, Haws RA, Gipson R and Santosham $\mathrm{M}$ : Practices of rural Egyptian birth attendants during the antenatal, intrapartum and early neonatal periods. J. Health Popul Nutr. 2008; 26 (1): 36-45.

20. Duong DV., Binns CW. And Lee AH. Utilization of delivery services at the primary health care level in rural Vietnam. Soc. Sci. Med., 2004; 59 (12): 2585-2595.

21. Amooti-Kaguna B. and Nuwaha F. Factors influencing choice of delivery sites in Rakai district of Uganda. Soc. Sci. Med., 2000; 50(2): 203-213.

22. D'ambruoso L., Abbey M. and Hussein J. Please understand when I cry out in pain: women's accounts of maternity services during labour and delivery in Ghana. BMC Public Health 2005; 5: 140.

23. Yanagisawa S., Oum S. and Wakai S. Determinants of skilled birth attendance in rural Cambodia. Tropical Medicine and International Health 2006; 11 (2): 238-251. doi:10.1111/j.13653156.2005.01547.x

24. Bell J., Curtis SL. and Alayon S. Trends in delivery care in six countries. DHS analytical studies No.7, ORC Macro and International Research Partnership for Skilled Attendance for
Everyone (SAFE). Calverton, Maryland USA. 2003.

25. Gage AJ., Guirlene Calixte M. Effects of the physical accessibility of maternal health services in their use in rural Haiti. Popul. Stud. (Camb.). 2006; 60(3): $271-288$.

26. Anthony S., Buitendijk S.E., Offerhaus P.M., van Dommelen P.,van der Pal-de Bruin K.M. Maternal factors and the probability of a planned home birth. International Journal of Obstetrics and Gynaecology 2005; 112: 748-753. DOI: $10.1111 /$ j.1471-0528.2004.00520.x 27. Stephenson R. and Tsui AO. Contextual influences on reproductive health services use in Uttar Pradesh, India. Stud. Fam. Plann. 2002; 33(4): 309 -320 .

28. Navaneetham K. and Dharmalingam A. Utilization of maternal health care services in Southern India. Soc. Sci. Med. 2002; 55(10): 1849-1869.

29. Glei DA, Goldman N and Rodriguez G: Utilization of care during pregnancy in rural Guatemala: does obstetrical need matter? Soc. Sci. Med., 2003; 57(12): 2447-2463.

30. Ghazi Tabatabaie M, Moudi Z and Vedadhir A: Home birth and barriers to referring women with obstetric complications to hospitals: a mixed methods study in Zahedan, southeastern Iran. Reproductive Health 2012, 9:5

31. Mrisho M., Schellenberg JA, Mushi Ak., Obrist B., Mshinda H., Tanner M. and Shellenberg D. Factors affecting home delivery in rural Tanzania. Trop. Med. Int. Health 2007; 12(7): 862-872.

32. Paul BK. and Rumsey DJ. Utilization of health facilities and trained birth attendants for childbirth in rural Bangladesh: an empirical study. Soc. Sci. Med. 2002; 54(12): 1755-1765. 